\title{
Stent thrombosis and optimal duration of dual antiplatelet therapy after coronary stenting in contemporary practice
}

\author{
Min Soo Cho and Duk-Woo Park
}

Department of Cardiology, Asan Medical Center, University of Ulsan College of Medicine, Seoul, Korea

Received: November 24, 2016 Accepted: August 3, 2017

\section{Correspondence to} Duk-Woo Park, M.D.

Department of Cardiology, Asan Medical Center, University of Ulsan College of Medicine, 88 Olympic-ro 43-gil, Songpa-gu, Seoul 05505, Korea

Tel: +82-2-3010-3995

Fax: +82-2-475-6898

E-mail: dwpark@amc.seoul.kr
The introduction of drug-eluting stents (DES) in the practice of percutaneous coronary intervention (PCI) has substantially reduced angiographic and clinical restenosis but is associated with an increasing propensity for very late stent thrombosis (ST). Among several clinical, lesion, or procedure-related predictors of ST, early discontinuation of dual antiplatelet therapy (DAPT) is the most important factor for DES-associated late thrombosis; therefore, the optimal duration of DAPT is a major issue to be critically considered in the current DES era. Given that the benefit and risk of longer duration DAPT should be simultaneously considered, the optimal DAPT period following DES implantation has been controversial. Several small-to-medium sized randomized clinical trials and observational registries have indicated that short-term DAPT ( $<6$ months) is not inferior to 12-month DAPT with fewer bleeding events, whereas prolonged duration of DAPT (> 12 months) failed to prove its superiority. However, compelling evidence from a landmark DAPT trial has clearly demonstrated the efficacy of prolonged DAPT up to 30 months in terms of preventing ST and major cardiovascular adverse events at the expense of major bleeding. In addition, coupled with various risk algorithms, a more individualized approach to balance the efficacy and safety of optimal DAPT duration has been emphasized. In this review article, we systematically summarize the cumulative evidence from key clinical studies and try to help the physician make decisions on the optimal duration of DAPT in contemporary PCI practice.

Keywords: Thrombosis; Drug-eluting stents; Platelet aggregation inhibitors; Percutaneous coronary intervention

\section{INTRODUCTION}

Percutaneous coronary intervention (PCI) has become remarkably advanced over recent decades in terms of device technology, procedural techniques/experiences, and pre-/post-PCI adjunctive pharmacology. In particular, the innovation and wide application of the drug-eluting stent (DES) is a fundamental component of such recent advancements [1]. DESs have dramatically reduced restenosis and the need for revascularization compared with bare-metal stents (BMSs) [2]; therefore, DESs have become the default PCI device, regardless of any clinical or lesion characteristics.

In contrast to the markedly improved efficacy of PCI with DESs, safety concerns for very late stent thrombosis (ST) have been raised. Although the absolute incidence 
of ST is quite low, most ST events manifest as an acute myocardial infarction (MI) or as acute coronary syndrome (ACS) with a high fatality rate [3-5]. Because endothelial coverage after implantation of a DES is relatively delayed and incomplete over the long-term and is the major pathological determinant of ST occurrence compared to BMSs [6-8], long-term dual antiplatelet therapy (DAPT) (i.e., aspirin plus a $\mathrm{P}_{2} \mathrm{Y}_{12}$ inhibitor) for 6 months to 1 year after implantation of a DES has been recommended by guidelines from the major societies $[9,10]$. However, prolonged DAPT is associated with a dose-dependent trade-off between increased risk of bleeding and decreased risk of ischemic events [11-13]. Additionally, the increased daily pill burden and limitations regarding endoscopic, dental, or surgical procedures following DAPT are other drawbacks of prolonged DAPT, which may affect patient quality of life $[14,15]$. Even after consecutive release of major clinical trials to determine the optimal duration of DAPT after DES placement, this issue of balancing efficacy and safety after DES implantation remains highly debated because "one size does not fit all" in diverse situations of real-world PCI practice. In the current review, we thoroughly evaluated the risk of ST after DES implantation in current PCI practice and systematically reviewed current available evidence regarding the optimal duration of DAPT.

\section{ST AFTER DES IMPLANTATION}

\section{Definition, time course, and incidence of ST after DES implantation}

The main ST pathophysiology is characterized by angiographic or post-mortem evidence of new thrombus formation at a previously stented site. A pathological study of an aspirated thrombus from a patient with ST showed a mixture of a platelet-rich thrombus, fibrin fragments, and inflammatory components, such as neutrophils and eosinophils [16]. Most patients with ST present with acute MI or ACS [3], but occasionally angiographic or pathological evidence is not available to clearly document ST. Therefore, an academic research consortium proposed reasonable criteria to standardize the definition [17], such as:

Definite: Angiographic confirmation of a ST that originates in the stent or in the segment $5 \mathrm{~mm}$ proximal or distal to the stent, with one of following criteria within
48 hours of angiography: acute onset of ischemic symptoms at rest; new ischemic electrocardiographic changes; typical rise and fall in cardiac biomarkers; or pathological confirmation of ST at autopsy or via examination of tissue retrieved after thrombectomy.

Probable: Unexplained death occurring within 30 days after the index procedure, or any MI that is related to documented acute ischemia in the territory of the implanted stent without angiographic confirmation.

Possible: Unexplained death occurring more than 30 days after the index procedure.

In addition, ST is classified into early (o to 30 days after index procedure), late (31 days to 1 year), and very late $>1$ year) events according to differences in the contribution of the pathophysiological processes and contributing factors in each category $[18,19]$. Most of the definite/probable ST events occur early after the index procedure ( $\leq 30$ days) with an overall incidence of $<1 \%$ in large registry data [1922]. However, there has been an ongoing risk of late and very late ST with cumulative incidence of $1.2 \%$ to $2.9 \%$ during 2 to 3 years of follow-up after DES implantation [18,23-25].

\section{ST in the era of first-generation and second-gener- ation DES}

Early ST is generally affected by procedural risk factors, such as stent under-sizing or under-expansion, presence of residual dissection, and residual disease at the edge of the stented segment [18]. However, incomplete endothelialization associated with the device platform plays an important role in patient- and procedure-related factors with regard to late-occurring ST. Autopsy studies have demonstrated that delayed arterial healing characterized by impaired endothelial coverage, persistent fibrin deposition, and ongoing vessel wall inflammation is an underlying pathophysiology for late ST after early generation DES implantation [26]. Among several factors associated with DES design, the durable polymer coating is a key factor predisposing for a higher risk of late ST $[27,28]$. For these reasons, second-generation DESs have been developed with technological improvements involving thinner stent struts, more biocompatible or bioabsorbable polymer coatings, and lower dosages of anti-proliferative drugs [29].

Some previous data show that the cumulative incidence of ST after first-generation DESs is not signifi- 
cantly different from that of BMSs [18,30]. However, several studies show a small but significant increase in late-occurring ST after first-generation DESs compared with BMSs [2,31]. In addition, some registry data provide evidence for a continuous increasing risk of ST even several years after a first-generation DES is implanted [23]. After wide-adoption of second-generation DESs, currently available registry data show a lower rate of ST in patients receiving everolimus eluting-stents (EES) compared to first generation DESs $[20,25]$. However, these data were insufficiently powered to prove the superiority of second generation DESs over first generation DESs. Indirect evidence from two large network meta-analyses is available and demonstrated a lower risk of ST in the EES compared to the BMS groups [32,33]. A subsequent meta-analysis comparing long-term outcomes (median, 3.8 years) of several DESs also showed a lower risk of ST, mortality, and MI in the EES compared to BMS or first generation DESs [34].

\section{Clinical importance of DAPT in the prevention of ST}

DAPT is a fundamental component of ST prevention. The efficacy of DAPT has been demonstrated in previous randomized controlled trials (RCTs) by comparing DAPT with single antiplatelet or anticoagulation therapy $[35,36]$. Most BMSs are almost completely endothelialized after 1 month, and are completely endothelialized after 3 to 6 months [37,38], but delayed and incomplete endothelialization is common even 6 to 12 months after DES implantation [6-8]. Therefore, 6- to 12-month DAPT is recommended by major interventional societies, but the recommendations are based largely on observational studies or expert opinions in the early period of DES. Subsequently, several medium-to-large sized RCTs have been performed to determine the optimal duration of DAPT after DES implantation.

\section{OPTIMAL DURATION OF DAPT}

\section{RCTs focusing on short-term DAPT (< 1 year)}

Six RCTs have been performed to determine the relative efficacy of 3 to 6 months of DAPT (Table 1). The Real Safety and Efficacy of 3-month Dual Antiplatelet Therapy following Endeavor Zotarolimus-Eluting Stent Implantation (RESET) [39] and Optimized Duration of
Clopidogrel Therapy Following Treatment with the Zotarolimus-Eluting Stent in Real-World Clinical Practice (OPTIMIZE) [40] trials compared 3-month DAPT with 12-month DAPT. DAPT longer than 6 months was compared with 12- or 24-month DAPT in the Efficacy of Xience/Promus versus Cypher to Reduce Late Loss After Stenting (EXCELLENT) [41], Second-Generation Drug-Eluting Stent Implantation Followed by Six- versus Twelve-Month Dual Antiplatelet Therapy (SECURITY) [42], Safety and Efficacy of Six-Month Dual Antiplatelet Therapy After Drug-Eluting Stenting (ISAR-SAFE) [43], and Is There A Life for DES after Discontinuation of Clopidogrel (ITALIC) [44] trials. These studies have uniformly proved the non-inferiority of short-term DAPT ( 3 to 6 months) compared to longer-term DAPT ( 12 to 24 months) with similar rates of ischemic events and lower rates of bleeding events. However, because of their non-inferiority design, the number of study subjects was insufficient to independently evaluate their efficacy on ST. In addition, a lower-than expected incidence of clinical events was another limitation in these studies. Lastly, most of these trials (except the ISAR-SAFE) randomized the patients at the time of PCI, not at the time when DAPT was discontinued, which may have diluted the treatment effects.

\section{RCTs focusing on long-term DAPT ( $>1$ year): impli- cations for a DAPT trial}

Five RCTs have been performed to determine the benefit of longer-term DAPT (> 12 months) compared to shorter-term DAPT (6 to 12 months) (Table 2). The Prolonged Dual Antiplatelet Treatment after Grading Stent-Induced Intimal Hyperplasia Study (PRODIGY) [45] compared 24-month DAPT to 6-month DAPT, and the Assessment by a Double Randomization of a Conventional Antiplatelet Strategy versus a Monitoring-guided Strategy for Drug-Eluting Stent Implantation and of Treatment Interruption versus Continuation One Year after stenting (ARCTIC)-interruption [46], the Optimal duration of dual antiplatelet therapy after drug-eluting stent implantation (DES-LATE) [47], the OPTImal DUAL antiplatelet therapy (OPTIDUAL) [48], and the DAPT [49] studies compared various durations of long-term DAPT (18 to 48 months) to 12-month DAPT. These studies were designed to prove the superiority of long-term DAPT, and randomized the patients at the time DAPT was dis- 
Table 1. Randomized clinical trials focusing on short-term DAPT ( $<1$ year)

\begin{tabular}{|c|c|c|c|c|c|c|c|}
\hline Trial & $\begin{array}{l}\text { No. of } \\
\text { patients }\end{array}$ & $\begin{array}{l}\text { Second } \\
\text { DES, \% }\end{array}$ & $\begin{array}{c}\mathrm{ACS}, \\
\%\end{array}$ & $\begin{array}{l}\text { Randomization, } \\
\text { mon }\end{array}$ & Primary endpoints & $\begin{array}{l}\text { Primary endpoints }{ }^{\mathrm{a}} \text {, } \\
\text { HR; } 95 \% \mathrm{CI} ; p \text { value }\end{array}$ & $\begin{array}{c}\text { ST, no. of } \\
\text { events/ } \\
\text { no. at risk }\end{array}$ \\
\hline OPTIMIZE [40] & 3,119 & 100 & $5 \cdot 4$ & 3 vs. 12 & $\begin{array}{l}\text { Death/MI/CVA/major } \\
\text { bleeding }\end{array}$ & $1.03 ; 0.77-1.38 ; 0.84$ & $\begin{array}{c}13 / 1,563 \text { vs. } \\
12 / 1,556\end{array}$ \\
\hline RESET [39] & 2,148 & 44.8 & 58.6 & 3 vs. 12 & $\begin{array}{l}\text { Cardiac death/MI/ST/ } \\
\text { TVR/ bleeding }\end{array}$ & $\begin{array}{l}\text { Risk difference } \\
0 ;-2.5 \text { to } 2.5 ; 0.84\end{array}$ & $\begin{array}{l}2 / 1,059 \text { vs. } \\
3 / 1,058\end{array}$ \\
\hline EXCELLENT [41] & 1,443 & 74.8 & 51.1 & 6 vs. 12 & $\begin{array}{l}\text { Cardiac death/MI/ } \\
\text { ischemia driven TVR }\end{array}$ & $1.14 ; 0.70-1.86 ; 0.60$ & $\begin{array}{l}6 / 722 \text { vs. } \\
1 / 721\end{array}$ \\
\hline ISAR-SAFE [43] & 4,000 & 88.6 & 40.0 & 6 vs. 12 & $\begin{array}{l}\text { Death/MI/ST/CVA/ } \\
\text { bleeding }\end{array}$ & $0.91 ; 0.55^{-1.50} ; 0.70$ & $\begin{array}{l}5 / 1,997 \text { vs. } \\
3 / 2,003^{c}\end{array}$ \\
\hline SECURITY [42] & 1,399 & 100 & 38.4 & 6 vs. 12 & $\begin{array}{l}\text { Cardiac death/MI/CVA/ } \\
\text { ST/ bleeding }\end{array}$ & $\begin{array}{l}\text { Risk difference } \\
3.7 ; 2.3-5.1 ; 0.469\end{array}$ & $\begin{array}{l}2 / 682 \text { vs. } \\
3 / 717\end{array}$ \\
\hline ITALIC [44] & 1,850 & 100 & 23.4 & 6 vs. 24 & $\begin{array}{l}\text { Death/MI/CVA/TVR/ } \\
\text { bleeding }\end{array}$ & $1.07 ; 0.52-2.22 ; 0.85$ & $\begin{array}{l}\text { 3/912 vs. } \\
\text { o/910 }\end{array}$ \\
\hline
\end{tabular}

DAPT, dual anti-platelet treatment; DES, drug-eluting stent; ACS, acute coronary syndrome; HR, hazard ratio; CI, confidence interval; ST, stent thrombosis; OPTIMIZE, Optimized Duration of Clopidogrel Therapy Following Treatment with the Zotarolimus-Eluting Stent in Real-World Clinical Practice; MI, myocardial infarction; CVA, cerebrovascular accident; RESET, Real Safety and Efficacy of 3-month Dual Antiplatelet Therapy following Endeavor Zotarolimus-Eluting Stent Implantation; TVR, target vessel revascularization; EXCELLENT, Efficacy of Xience/Promus versus Cypher to Reduce Late Loss After Stenting; ISAR-SAFE, Safety and Efficacy of Six-Month Dual Antiplatelet Therapy After Drug-Eluting Stenting; SECURITY, Second-Generation Drug-Eluting Stent Implantation Followed by Six- versus Twelve-Month Dual Antiplatelet Therapy; ITALIC, Is There A Life for DES after Discontinuation of Clopidogrel.

${ }^{a}$ Results are HR for short-term DAPT ( 3 to 6 months) compared to 12 to 24 months DPAT; $p$ values were for superiority.

${ }^{\mathrm{b}}$ Definite or probable stent thrombosis.

'Only incidence of definite stent thrombosis was available.

Table 2. Randomized clinical trials focusing on long-term DAPT (> 1 year)

\begin{tabular}{|c|c|c|c|c|c|c|c|}
\hline Trial & $\begin{array}{c}\text { No. of } \\
\text { patients }\end{array}$ & $\begin{array}{l}\text { Second } \\
\text { DES, \% }\end{array}$ & ACS, $\%$ & $\begin{array}{c}\text { Randomization, } \\
\text { mon }\end{array}$ & $\begin{array}{l}\text { Primary } \\
\text { endpoints }\end{array}$ & $\begin{array}{l}\text { Primary endpoints }^{\mathrm{a}} \text {, } \\
\text { HR; } 95 \% \text { CI; } p \text { value }\end{array}$ & $\begin{array}{c}\text { ST, no. of event/ } \\
\text { no. at risk }\end{array}$ \\
\hline PRODIGY [45] & 1,399 & 50.2 & 38.4 & 6 vs. 24 & Death/MI/CVA & $0.98 ; 0.74-1.29 ; 0.91$ & $15 / 983$ vs. $13 / 987$ \\
\hline $\begin{array}{l}\text { ARCTIC- } \\
\text { interruption [46] }\end{array}$ & 1,259 & 62.6 & NR & 12 vs. $18-24$ & $\begin{array}{l}\text { Death/MI/ST/ } \\
\text { CVA/TVR }\end{array}$ & $1.17 ; 0.68-2.03 ; 0.58$ & 3/624 vs. o/635 \\
\hline DES-LATE [47] & 5,045 & 29.4 & 60.7 & 12 vs. 36 & $\begin{array}{l}\text { Cardiac death/MI/ } \\
\text { CVA }\end{array}$ & $0.94 ; 0.66-1.35 ; 0.75$ & $\begin{array}{l}11 / 2,514 \text { vs. } \\
7 / 2,531^{c}\end{array}$ \\
\hline OPTIDUAL [48] & 1,385 & $59 \cdot 3$ & - & 12 vs. 48 & $\begin{array}{l}\text { Death/MI/stroke/ } \\
\text { major bleeding }\end{array}$ & $0.75 ; 0.50-1.28 ; 0.17$ & o/69o vs. 3/695 \\
\hline DAPT [49] & 9,961 & 59.9 & 42.6 & 12 vs. 30 & $\begin{array}{l}\text { ST } \\
\text { MACE (death/MI/ } \\
\text { stroke) }\end{array}$ & $\begin{array}{l}3.45 ; 2.08-5.88 \\
<0.001 \text { for } \mathrm{ST} \\
1.41 ; 1.18-1.69 \\
<0.001 \text { for MACE }\end{array}$ & $\begin{array}{l}65 / 4,941 \text { vs. } \\
19 / 5,020\end{array}$ \\
\hline
\end{tabular}

DAPT, dual anti-platelet treatment; DES, drug-eluting stent; ACS, acute coronary syndrome; HR, hazard ratio; CI, confidence interval; ST, stent thrombosis; PRODIGY, Prolonged Dual Antiplatelet Treatment after Grading Stent-Induced Intimal Hyperplasia Study; MI, myocardial infarction; CVA, cerebrovascular accident; ARCTIC, Assessment by a Double Randomization of a Conventional Antiplatelet Strategy versus a Monitoring-guided Strategy for Drug-Eluting Stent Implantation and of Treatment Interruption versus Continuation One Year after stenting; NR, not reported; TVR, target vessel revascularization; DESLATE, duration of clopidogrel therapy after drug-eluting stent; OPTIDUAL, OPTImal DUAL antiplatelet therapy; MACE, major adverse cardiovascular event.

${ }^{\text {a }}$ Results are HR of short-term DAPT ( 3 to 6 months) compared to the 12 to 24 months DPAT; $p$ values were for superiority.

${ }^{\mathrm{b}}$ Definite or probable stent thrombosis.

${ }^{\mathrm{c}}$ Only incidence of definite stent thrombosis was available. 
continued (except the PRODIGY trial). Therefore, these studies were able to directly speculate on the effect of prolonged DAPT after DES implantation. However, the ARCTIC-interruption, PRODIGY, DES-LATE, and OPTIDUAL trials failed to prove superiority in terms of their composite primary outcomes. These studies also shared limitations of an open-label design and a lower than expected event rate, which could be associated with underpowered results.

The largest DAPT trial provided the superiority of long-term (30 months) over standard duration (12 months) DAPT. Overall, 9,921 patients were randomized to receive aspirin plus clopidogrel or aspirin plus placebo treatments after completing 12-month DAPT. As a result, long-term DAPT up to 30 months clearly decreased the risk of ST (hazard ratio [HR], 0.29; 95\% confidence interval [CI], 0.17 to $0.48 ; p<0.001)$ and composite of death, MI, or stroke (HR, 0.71; 95\% CI, 0.59 to 0.85 ; $p<$ o.oo1) compared to standard DAPT. At the expense of an improved efficacy outcome, this study also showed an increased risk for moderate to severe bleeding (2.5\% vs. $1.6 \%, p=0.001)$ and an increased rate of all-cause mortality in the long-term DAPT arm (2.0\% vs. $1.5 \%, p=0.05)$. Most of the extra mortality in the long-term DAPT arm was non-cardiac cause ( $1.0 \%$ vs. $0.5 \%, p=0.002$ ), which might be explained by a chance effect or the enrollment of a large number of patients with cancer in this arm. The DAPT trial has unique strengths over other studies that focused on the efficacy of long-term DAPT. This study was a placebo-controlled trial, which minimizes potential selection bias compared to other open-label studies. In addition, the number of participants in the DAPT study was larger than the sum of all other trials and provided sufficient power for proving their superiority hypothesis and generalizability.

The results of several meta-analyses have been published. A network meta-analysis from Palmerini et al. [50] showed that those receiving shorter-term DAPT ( $\leq$ 12 months) had a higher risk of definite or probable ST (HR, 2.50; 95\% CI, 1.70 to 4.00) and MI (HR, 1.60; 95\% CI, 1.40 to 2.10$)$ compared to patients receiving longer-term DAPT (> 12 months), but a lower risk of major bleeding (HR, 0.58; 95\% CI, 0.45 to 0.74 ) and all-cause death (HR, 0.82; $95 \%$ CI, 0.65 to 1.00), mainly driven by non-cardiac causes. Similarly, another meta-analysis by Giustino et al. [51] also showed similar findings (odd ratio [OR],
1.71; $95 \%$ CI, 1.26 to $2.32 ; p=0.001$ for ST) $(\mathrm{OR}, 1.39 ; 95 \%$ CI, 1.20 to $1.62 ; p<0.001$ for $\mathrm{MI}$ ) (OR, $0.63 ; 95 \% \mathrm{CI}, 0.52$ to $0.75 ; p<0.001$ for major bleeding), except the OR for all-cause mortality was not significant (OR, 0.87; 95\% CI, 0.74 to $1.01 ; p=0.073)$.

Although the interaction term between DES type and DAPT was not significant in the DAPT trial ( $p$ for interaction $=0.76)$, more than half of the ST events $(57.1 \%$, 48/84) occurred in patients receiving a paclitaxel-eluting stent. Similarly, the meta-analysis by Giustino et al. [51] reported that the risk for ST in short-term to longterm DAPT was more exaggerated with first generation DESs (OR, 3.94; 95\% CI, 2.20 to 7.05) compared to that of second generation DESs (OR, 1.54; 95\% CI, 0.96 to 2.47; $p$ for interaction $=0.008)$. In addition, another co-primary endpoint of MACE (major adverse cardiovascular event; defined as composite of death, stroke, and MI) also showed a significant interaction with stent type ( $p$ for interaction $=0.048$ ), with a lesser effect of prolonged DAPT in second generation DESs. Such findings indicate that the effect of long-term DAPT on ST prevention could be attenuated in the current era of second generation DES, and the result from the DAPT study should be cautiously applicable in contemporary PCI practice.

\section{CURRENT GUIDELINE RECOMMENDATIONS FOR DAPT DURATION}

The traditional concept of 6 to 12 months of DAPT has not been supported by strong and compelling evidence based on RCT data; therefore, it might not be surprising that there have been some inconsistencies across recommendations from major societies. However, after publication of a series of major trials, a more reliable recommendation has been suggested (Tables 3 and 4). In the 2016 focused updates on the duration of DAPT, the American College of Cardiology Foundation/American Heart Association/Society for Cardiovascular Angiography and Interventions (ACCF/AHA/SCAI) recommended a minimum duration decrease from 12 to 6 months among patients with stable coronary artery disease (CAD) treated with DES [52]. This recommendation was based on the lower risk of ST from newer-generation DESs and comparable results of RCTs comparing shortterm versus 12-month DAPT (Table 1). In addition, there 
Table 3. Current updated guideline recommendations on optimal duration of DAPT: stable coronary artery disease

\begin{tabular}{|c|c|c|}
\hline ACCF/AHA/SCAI 2016 & Class & Level \\
\hline $\begin{array}{l}\text { P2Y } 12 \text { inhibitor therapy with clopidogrel should be given for a minimum of } 1 \text { month to patients } \\
\text { with SIHD treated with DAPT after BMS implantation. }\end{array}$ & I & A \\
\hline $\begin{array}{l}\mathrm{P}_{2} \mathrm{Y} 12 \text { inhibitor therapy with clopidogrel should be given for at least } 6 \text { months to patients with } \\
\text { SIHD treated with DAPT after DES implantation. }\end{array}$ & I & $\mathrm{B}$ \\
\hline $\begin{array}{l}\text { DAPT should be continued with clopidogrel for }>1 \text { month in patients treated with a BMS } \\
\text { or }>6 \text { months in patients treated with a DES for those with SIHD treated with DAPT after BMS } \\
\text { or DES implantation who have tolerated DAPT without a bleeding complication and who are not at } \\
\text { high bleeding risk (e.g., prior bleeding on DAPT, coagulopathy, oral anticoagulant use). }\end{array}$ & IIb & A \\
\hline $\begin{array}{l}\text { P2Y } 12 \text { inhibitor therapy should be discontinued after } 3 \text { months in patients with SIHD treated } \\
\text { with DAPT after DES implantation who develop a high risk of bleeding (e.g., treatment with } \\
\text { oral anticoagulant therapy), are at high risk of a severe bleeding complication (e.g., major } \\
\text { intracranial surgery), or develop significant overt bleeding. }\end{array}$ & $\mathrm{IIb}$ & $\mathrm{C}$ \\
\hline \multicolumn{3}{|l|}{ ESC/EACTS 2014} \\
\hline DAPT is indicated for at least 1 month after BMS implantation. & I & A \\
\hline DAPT is indicated for 6 months after DES implantation. & I & $\mathrm{B}$ \\
\hline $\begin{array}{l}\text { Shorter DAPT duration (<6 months) may be considered after DES implantation in patients at } \\
\text { high risk for bleeding. }\end{array}$ & IIb & A \\
\hline Life-long single antiplatelet therapy, usually ASA, is recommended. & I & A \\
\hline DAPT may be used for $>6$ months in patients at high ischemic risk and low bleeding risk. & IIb & C \\
\hline
\end{tabular}

DAPT, dual anti-platelet treatment; ACCF, American College of Cardiology Foundation; AHA, American Heart Association; SCAI, Society for Cardiovascular Angiography and Interventions; SIHD, stable ischemic heart disease; BMS, bare-metal stent; DES, drug-eluting stent; ESC, European Society of Cardiology; EACTS, European Association for Cardio-Thoracic Surgery; ASA, acetylsalicylic acid.

Table 4. Current updated guideline recommendations on optimal duration of DAPT: acute coronary syndrome

\begin{tabular}{|c|c|c|}
\hline ACCF/AHA/SCAI 2016 & Class & Level \\
\hline $\begin{array}{l}\text { P2Y } 12 \text { inhibitor therapy (clopidogrel, prasugrel, or ticagrelor) should be given for at least } \\
12 \text { months to patients with ACS (NSTE-ACS or STEMI) treated with DAPT after BMS or } \\
\text { DES implantation. }\end{array}$ & I & B \\
\hline $\begin{array}{l}\text { It may be reasonable to continue DAPT (clopidogrel, prasugrel, or ticagrelor) for }>12 \text { months } \\
\text { in patients with ACS (NSTE-ACS or STEMI) treated with coronary stent implantation who } \\
\text { have tolerated DAPT without a bleeding complication and who are not at high bleeding risk } \\
\text { (e.g., prior bleeding on DAPT, coagulopathy, oral anticoagulant use). }\end{array}$ & IIb & A \\
\hline $\begin{array}{l}\text { Discontinuing } \mathrm{P}_{2} \mathrm{Y} 12 \text { inhibitor therapy may be reasonable after } 6 \text { months in patients with } \\
\text { ACS treated with DAPT after DES implantation who develop a high risk of bleeding } \\
\text { (e.g., treatment with oral anticoagulant therapy), are at high risk of severe bleeding } \\
\text { complication (e.g., major intracranial surgery), or develop significant overt bleeding. }\end{array}$ & IIb & $\mathrm{C}$ \\
\hline \multicolumn{3}{|l|}{ ESC/EACTS 2014} \\
\hline $\begin{array}{l}\text { A P2Y } 12 \text { inhibitor is recommended in addition to ASA and should be maintained over } 12 \text { months } \\
\text { unless there are contraindications such as excessive risk of bleeding. }\end{array}$ & I & A \\
\hline
\end{tabular}

DAPT, dual anti-platelet treatment; ACCF, American College of Cardiology Foundation; AHA, American Heart Association; SCAI, Society for Cardiovascular Angiography and Interventions; NSTE-ACS, non-ST-elevation acute coronary syndromes; STEMI, ST-elevation myocardial infarction; BMS, bare-metal stent; DES, drug-eluting stent; ESC, European Society of Cardiology; EACTS, European Association for Cardio-Thoracic Surgery; ASA, acetylsalicylic acid. 
Table 5. Elements of the DAPT score (total score range, -2 to 10$)$

\begin{tabular}{lc}
\hline Variable & Points \\
\hline Age, yr & \\
$\geq 75$ & -2 \\
$65-75$ & -1 \\
$<65$ & 0 \\
Smoking & 1 \\
Diabetes mellitus & 1 \\
MI at presentation & 1 \\
Prior PCI or MI & 1 \\
Paclitaxel-eluting stent & 1 \\
Stent diameter $<3$ mm & 1 \\
CHF or LVEF $<30$ & 2 \\
\hline Vein graft stent & 2 \\
\hline Adapted from Yeh et al. with permission from American
\end{tabular}

Adapted from Yeh et al., with permission from American Medical Association [53]. A score $\geq 2$ is associated with a favorable benefit/risk ratio for prolonged DAPT, whereas a score $<2$ is associated with an unfavorable benefit/risk ratio. DAPT, dual anti-platelet treatment; MI, myocardial infarction; PCI, percutaneous coronary intervention; $\mathrm{CHF}$, congestive heart failure; LVEF, left ventricular ejection fraction.

were two class IIb recommendations that considered efficacy (prevention of ST and ischemic events) and risk (bleeding) in individuals. In patients with stable CAD who underwent DES implantation, 3 months of DAPT was reasonable in patients with a high risk of bleeding. In contrast, more than 6 months of 'standard' DAPT may also be reasonable in patients without such risk. In the setting of ACS, at least 12 months of DAPT was sustained, but 6-month DAPT in high-bleeding risk patients and > 12-month DAPT in those not at risk for high bleeding may also be reasonable (class IIB).

These updated guidelines have two important clinical implications. First, the guidelines from two major societies (ACCF/AHA/SCAI and European Society of Cardiology/European Association for Cardio-Thoracic Surgery) shared similar recommendations on DAPT duration, which reflects the stronger supporting evidence compared with the previous guidelines. Second, more individualized DAPT duration is recommended in both guidelines, which is in line with the concept of 'personalized medicine.' Therefore, predicting each patient's risk and benefit from long-term DAPT is currently an area of importance.

\section{RISK PREDICTION MODEL TO DEFINE OPTI- MAL DAPT DURATION}

Yeh et al. [53] established a scoring system that classified patients who could mostly benefit from longer duration DAPT based on the DAPT trial. The scoring system consisted of one negative component (age) and eight positive components (smoking, diabetes, MI at presentation, prior PCI or MI, paclitaxel-eluting stent, stent diameter $<3 \mathrm{~mm}$, congestive heart failure or left ventricular ejection fraction $<30 \%$, and vein graft stent) (Table 5). Patients with a DAPT score $\geq 2$ had a larger reduction in MI or ST with long-term DAPT (risk difference [RD], $-3.0 \%$; $95 \% \mathrm{CI},-4.1$ to $-2.0 ; p<0.001)$ compared to those with a DAPT score < 2 (RD, -0.7\%; 95\% CI, -1.4 to 0.09; $p=0.07 ; p$ for interaction $<0.001)$. In contrast, the low score group showed a significant increase in bleeding risk ( $\mathrm{RD}, 1.5 \%$; 95\% CI, 0.8 to 2.3 ; $p<0.001$ ) compared with that in the high score group (RD, $0.4 \%$; $95 \% \mathrm{CI},-0.3$ to 1.0; $p=0.26 ; p$ for interaction $=0.02$ ). Although the direct application of such a system might be limited due to its modest discriminating performance in the original cohort (c-statistic 0.70 for the ischemia model; 0.68 for the bleeding model) and even reduced discrimination in external validation, the scoring system itself is an important attempt in terms of 'personalized medicine,' which balances the benefit and risk ratio of prolonged DAPT therapy among patients receiving DES implantation.

\section{BIOABSORBABLE VASCULAR SCAFFOLD THROMBOSIS AND OPTIMAL DAPT DURA- TION}

Bioabsorbable vascular scaffolds (BVSs) are a currently emerging interventional technology of interest characterized by transient arterial support and self-degradation, which are expected to have a benefit over permanent metallic DESs [54]. Several RCTs have shown that clinical outcomes after BVS implantation are comparable to those of currently used DESs [55-60]. However, 
notwithstanding its comparable efficacy and conceptual advantage, concerns about a higher rate of early ST compared to contemporary DESs were recently issued. Puricel et al. [61] showed that ST occurred in 3\% $(42 / 1,305)$ of the total population treated with BVSs during a 12-month follow-up. Half of the ST events occurred during the early period (<30 days) after implantation, and the others occurred during the late period, reflecting the ongoing risk of ST over time. The higher risk of ST with the use of BVSs compared to DESs was consistently found in two large meta-analyses from Stone et al. [59] (OR, 2.09; 95\% CI, 0.92 to 4.75) [59] and Cassese et al. [6o] (OR, 1.99; 95\% CI, 1.00 to 3.95). This higher risk of thrombosis might be related to mechanical factors (i.e., under-expansion, loss of BVS integrity with subsequent mal-apposition, or anomalous resorption) and suspended or inadequate anti-platelet treatment [61-63]. To date, the major interventional societies have not made any recommendations on DAPT duration following BVS implantation. More compelling evidence from a RCT or large registry data would be required to determine the optimal DAPT duration following BVS implantation.

\section{CONCLUSIONS}

Although the efficacy of prolonged DAPT to reduce ischemic events after DES implantation was proved in the DAPT trial, their results could be different in contemporary practice, as more advanced DES with biocompatible or biodegradable polymers have been widely used recently [64]. In addition, large-sized data from observational registries would be required to complement the key findings of RCTs in "real-world" clinical practice. BVSs are another new challenge in terms of determining DAPT duration. Although patients who receive currently available BVSs seem to be at potentially higher risk of early ST, optimal DAPT duration following BVS implantation should be determined in large-sized clinical trials with a long-term follow-up. In addition, most previous DAPT trials were designed to use aspirin as the backbone drug and to test the additional efficacy and safety of $\mathrm{P}_{2} \mathrm{Y}_{12}$ receptors as a controlled intervention. However, clopidogrel alone potentially could have similar or slightly better efficacy than that of aspirin alone for preventing recurrent ischemic events [65]. Therefore, data on single-use clopidogrel or newer P2Y12 blockers (prasugrel or ticagrelor) compared to prolonged DAPT would also be interesting; the ongoing GLOBAL LEADERS (comparative effectiveness of 1 month of ticagrelor plus aspirin followed by ticagrelor monotherapy versus a current-day intensive dual antiplatelet therapy in all-comers patients undergoing percutaneous coronary intervention with bivalirudin and biomatrix family drug-eluting stent use) trial (NCTo1813435) and the STAMP-DES (short-term dual antiplatelet and maintenance clopidogrel therapy after drug-eluting stent implantation) trial (NCTo2494284) will provide a reliable answer to this issue.

In conclusion, DAPT is a fundamental component of post-PCI care for the prevention of ST and major adverse events. Based on currently available evidence, 6 to 12 months of DAPT are recommended following DES implantation. Decisions about the duration of DAPT are best made on an individual basis and should integrate clinical judgment, assessment of the benefit/risk ratio, and patient preference.

\section{Conflict of interest}

No potential conflict of interest relevant to this article was reported.

\section{REFERENCES}

1. Stefanini GG, Holmes DR Jr. Drug-eluting coronary-artery stents. N Engl J Med 2013;368:254-265.

2. Stettler C, Wandel S, Allemann S, et al. Outcomes associated with drug-eluting and bare-metal stents: a collaborative network meta-analysis. Lancet 2007;370:937-948.

3. Armstrong EJ, Feldman DN, Wang TY, et al. Clinical presentation, management, and outcomes of angiographically documented early, late, and very late stent thrombosis. JACC Cardiovasc Interv 2012;5:131-140.

4. Schulz S, Schuster T, Mehilli J, et al. Stent thrombosis after drug-eluting stent implantation: incidence, timing, and relation to discontinuation of clopidogrel therapy over a 4-year period. Eur Heart J 2009;30:2714-2721.

5. Holmes DR Jr, Kereiakes DJ, Garg S, et al. Stent thrombosis. J Am Coll Cardiol 2010;56:1357-1365.

6. Nakazawa G, Finn AV, Joner M, et al. Delayed arterial healing and increased late stent thrombosis at culprit 
sites after drug-eluting stent placement for acute myocardial infarction patients: an autopsy study. Circulation 2008;118:1138-1145.

7. Kotani J, Awata M, Nanto S, et al. Incomplete neointimal coverage of sirolimus-eluting stents: angioscopic findings. J Am Coll Cardiol 2006;47:2108-2111.

8. Finn AV, Joner M, Nakazawa G, et al. Pathological correlates of late drug-eluting stent thrombosis: strut coverage as a marker of endothelialization. Circulation 2007;115:2435-2441.

9. Kolh P, Windecker S, Alfonso F, et al. 2014 ESC/EACTS guidelines on myocardial revascularization: the Task Force on Myocardial Revascularization of the European Society of Cardiology (ESC) and the European Association for Cardio-Thoracic Surgery (EACTS). Developed with the special contribution of the European Association of Percutaneous Cardiovascular Interventions (EAPCI). Eur J Cardiothorac Surg 2014;46:517-592.

10. Levine GN, Bates ER, Blankenship JC, et al. 2011 ACCF/ AHA/SCAI guideline for percutaneous coronary intervention: executive summary. A report of the American College of Cardiology Foundation/American Heart Association Task Force on Practice Guidelines and the Society for Cardiovascular Angiography and Interventions. Circulation 2011;124:2574-2609.

11. Berger PB, Bhatt DL, Fuster V, et al. Bleeding complications with dual antiplatelet therapy among patients with stable vascular disease or risk factors for vascular disease: results from the Clopidogrel for High Atherothrombotic Risk and Ischemic Stabilization, Management, and Avoidance (CHARISMA) trial. Circulation 2010;121:2575-2583.

12. Bowry AD, Brookhart MA, Choudhry NK. Meta-analysis of the efficacy and safety of clopidogrel plus aspirin as compared to antiplatelet monotherapy for the prevention of vascular events. Am J Cardiol 2008;101:960-966.

13. Doyle BJ, Rihal CS, Gastineau DA, Holmes DR Jr. Bleeding, blood transfusion, and increased mortality after percutaneous coronary intervention: implications for contemporary practice. J Am Coll Cardiol 2009;53:20192027.

14. Iwata Y, Kobayashi Y, Fukushima K, et al. Incidence of premature discontinuation of antiplatelet therapy after sirolimus-eluting stent implantation. Circ J 2008;72:340341.

15. Cho YK, Nam CW, Park HS, et al. Efficacy and safety of antiplatelet-combination therapy after drug-eluting stent implantation. Korean J Intern Med 2014;29:210-216.

16. Riegger J, Byrne RA, Joner M, et al. Histopathological evaluation of thrombus in patients presenting with stent thrombosis. A multicenter European study: a report of the prevention of late stent thrombosis by an interdisciplinary global European effort consortium. Eur Heart J 2016;37:1538-1549.

17. Cutlip DE, Windecker S, Mehran R, et al. Clinical end points in coronary stent trials: a case for standardized definitions. Circulation 2007;115:2344-2351.

18. van Werkum JW, Heestermans AA, Zomer AC, et al. Predictors of coronary stent thrombosis: the Dutch Stent Thrombosis Registry. J Am Coll Cardiol 2009;53:13991409.

19. Tada T, Byrne RA, Simunovic I, et al. Risk of stent thrombosis among bare-metal stents, first-generation drug-eluting stents, and second-generation drug-eluting stents: results from a registry of 18,334 patients. JACC Cardiovasc Interv 2013;6:1267-1274.

20. Raber L, Magro M, Stefanini GG, et al. Very late coronary stent thrombosis of a newer-generation everolimus-eluting stent compared with early-generation drug-eluting stents: a prospective cohort study. Circulation 2012;125:1110-1121.

21. Stone GW, Witzenbichler B, Weisz G, et al. Platelet reactivity and clinical outcomes after coronary artery implantation of drug-eluting stents (ADAPT-DES): a prospective multicentre registry study. Lancet 2013;382:614-623.

22. Palmerini T, Kirtane AJ, Serruys PW, et al. Stent thrombosis with everolimus-eluting stents: meta-analysis of comparative randomized controlled trials. Circ Cardiovasc Interv 2012;5:357-364.

23. Daemen J, Wenaweser P, Tsuchida K, et al. Early and late coronary stent thrombosis of sirolimus-eluting and paclitaxel-eluting stents in routine clinical practice: data from a large two-institutional cohort study. Lancet 2007;369:667-678.

24. Airoldi F, Colombo A, Morici N, et al. Incidence and predictors of drug-eluting stent thrombosis during and after discontinuation of thienopyridine treatment. Circulation 2007;116:745-754.

25. Lagerqvist B, Carlsson J, Frobert O, et al. Stent thrombosis in Sweden: a report from the Swedish Coronary Angiography and Angioplasty Registry. Circ Cardiovasc Interv 2009;2:401-408.

26. Finn AV, Nakazawa G, Joner M, et al. Vascular responses to drug eluting stents: importance of delayed healing. Ar- 
terioscler Thromb Vasc Biol 2007;27:1500-1510.

27. Byrne RA, Joner M, Kastrati A. Polymer coatings and delayed arterial healing following drug-eluting stent implantation. Minerva Cardioangiol 2009;57:567-584.

28. Luscher TF, Steffel J, Eberli FR, et al. Drug-eluting stent and coronary thrombosis: biological mechanisms and clinical implications. Circulation 2007;115:1051-1058.

29. Kolandaivelu K, Swaminathan R, Gibson WJ, et al. Stent thrombogenicity early in high-risk interventional settings is driven by stent design and deployment and protected by polymer-drug coatings. Circulation 2011;123:1400-1409.

30. Weisz G, Leon MB, Holmes DR Jr, et al. Five-year follow-up after sirolimus-eluting stent implantation results of the SIRIUS (Sirolimus-Eluting Stent in De-Novo Native Coronary Lesions) Trial. J Am Coll Cardiol 2009;53:14881497 .

31. Stone GW, Moses JW, Ellis SG, et al. Safety and efficacy of sirolimus- and paclitaxel-eluting coronary stents. N Engl J Med 2007;356:998-1008.

32. Palmerini T, Biondi-Zoccai G, Della Riva D, et al. Stent thrombosis with drug-eluting and bare-metal stents: evidence from a comprehensive network meta-analysis. Lancet 2012;379:1393-1402.

33. Bangalore S, Kumar S, Fusaro M, et al. Short- and longterm outcomes with drug-eluting and bare-metal coronary stents: a mixed-treatment comparison analysis of 117,762 patient-years of follow-up from randomized trials. Circulation 2012;125:2873-2891.

34. Palmerini T, Benedetto U, Biondi-Zoccai G, et al. Longterm safety of drug-eluting and bare-metal stents: evidence from a comprehensive network meta-analysis. J Am Coll Cardiol 2015;65:2496-2507.

35. Leon MB, Baim DS, Popma JJ, et al. A clinical trial comparing three antithrombotic-drug regimens after coronary-artery stenting: Stent Anticoagulation Restenosis Study Investigators. N Engl J Med 1998;339:1665-1671.

36. Schomig A, Neumann FJ, Kastrati A, et al. A randomized comparison of antiplatelet and anticoagulant therapy after the placement of coronary-artery stents. N Engl J Med 1996;334:1084-1089.

37. Ueda Y, Nanto S, Komamura K, Kodama K. Neointimal coverage of stents in human coronary arteries observed by angioscopy. J Am Coll Cardiol 1994;23:341-346.

38. Bergeron P, Rudondy P, Poyen V, Pinot JJ, Alessandri C, Martelet JP. Long-term peripheral stent evaluation using angioscopy. Int Angiol 1991;10:182-186.
39. Kim BK, Hong MK, Shin DH, et al. A new strategy for discontinuation of dual antiplatelet therapy: the RESET Trial (REal Safety and Efficacy of 3-month dual antiplatelet Therapy following Endeavor zotarolimus-eluting stent implantation). J Am Coll Cardiol 2012;60:1340-1348.

40. Feres F, Costa RA, Abizaid A, et al. Three vs twelve months of dual antiplatelet therapy after zotarolimus-eluting stents: the OPTIMIZE randomized trial. JAMA 2013;310:2510-2522.

41. Gwon HC, Hahn JY, Park KW, et al. Six-month versus 12-month dual antiplatelet therapy after implantation of drug-eluting stents: the Efficacy of Xience/Promus Versus Cypher to Reduce Late Loss After Stenting (EXCELLENT) randomized, multicenter study. Circulation 2012;125:505513.

42. Colombo A, Chieffo A, Frasheri A, et al. Second-generation drug-eluting stent implantation followed by 6- versus 12-month dual antiplatelet therapy: the SECURITY randomized clinical trial. J Am Coll Cardiol 2014;64:20862097.

43. Schulz-Schupke S, Byrne RA, Ten Berg JM, et al. ISAR-SAFE: a randomized, double-blind, placebo-controlled trial of 6 vs. 12 months of clopidogrel therapy after drug-eluting stenting. Eur Heart J 2015;36:1252-1263.

44. Gilard M, Barragan P, Noryani AA, et al. 6- versus 24-month dual antiplatelet therapy after implantation of drug-eluting stents in patients nonresistant to aspirin: the randomized, multicenter ITALIC trial. J Am Coll Cardiol 2015;65:777-786.

45. Valgimigli M, Campo G, Monti M, et al. Short- versus long-term duration of dual-antiplatelet therapy after coronary stenting: a randomized multicenter trial. Circulation 2012;125:2015-2026.

46. Collet JP, Silvain J, Barthelemy O, et al. Dual-antiplatelet treatment beyond 1 year after drug-eluting stent implantation (ARCTIC-Interruption): a randomised trial. Lancet 2014;384:1577-1585.

47. Lee CW, Ahn JM, Park DW, et al. Optimal duration of dual antiplatelet therapy after drug-eluting stent implantation: a randomized, controlled trial. Circulation 2014;129:304312.

48. Helft G, Steg PG, Le Feuvre C, et al. Stopping or continuing clopidogrel 12 months after drug-eluting stent placement: the OPTIDUAL randomized trial. Eur Heart J 2016;37:365-374.

49. Mauri L, Kereiakes DJ, Yeh RW, et al. Twelve or 30 months 
of dual antiplatelet therapy after drug-eluting stents. $\mathrm{N}$ Engl J Med 2014;371:2155-2166.

50. Palmerini T, Benedetto U, Bacchi-Reggiani L, et al. Mortality in patients treated with extended duration dual antiplatelet therapy after drug-eluting stent implantation: a pairwise and Bayesian network meta-analysis of randomised trials. Lancet 2015;385:2371-2382.

51. Giustino G, Baber U, Sartori S, et al. Duration of dual antiplatelet therapy after drug-eluting stent implantation: a systematic review and meta-analysis of randomized controlled trials. J Am Coll Cardiol 2015;65:1298-1310.

52. Levine GN, Bates ER, Bittl JA, et al. 2016 ACC/AHA guideline focused update on duration of dual antiplatelet therapy in patients with coronary artery disease: a report of the American College of Cardiology/American Heart Association Task Force on Clinical Practice Guidelines. J Am Coll Cardiol 2016;68:1082-1115.

53. Yeh RW, Secemsky EA, Kereiakes DJ, et al. Development and validation of a prediction rule for benefit and harm of dual antiplatelet therapy beyond 1 year after percutaneous coronary intervention. JAMA 2016;315:1735-1749.

54. Iqbal J, Onuma Y, Ormiston J, Abizaid A, Waksman R, Serruys $P$. Bioresorbable scaffolds: rationale, current status, challenges, and future. Eur Heart J 2014;35:765-776.

55. Ellis SG, Kereiakes DJ, Metzger DC, et al. Everolimus-eluting bioresorbable scaffolds for coronary artery disease. N Engl J Med 2015;373:1905-1915.

56. Serruys PW, Chevalier B, Dudek D, et al. A bioresorbable everolimus-eluting scaffold versus a metallic everolimus-eluting stent for ischaemic heart disease caused by de-novo native coronary artery lesions (ABSORB II): an interim 1-year analysis of clinical and procedural secondary outcomes from a randomized controlled trial. Lancet 2015;385:43-54.

57. Kimura T, Kozuma K, Tanabe K, et al. A randomized trial evaluating everolimus-eluting Absorb bioresorbable scaf- folds vs. everolimus-eluting metallic stents in patients with coronary artery disease: ABSORB Japan. Eur Heart J 2015;36:3332-3342.

58. Gao R, Yang Y, Han Y, et al. Bioresorbable vascular scaffolds versus metallic stents in patients with coronary artery disease: ABSORB China Trial. J Am Coll Cardiol 2015;66:2298-2309.

59. Stone GW, Gao R, Kimura T, et al. 1-Year outcomes with the absorb bioresorbable scaffold in patients with coronary artery disease: a patient-level, pooled meta-analysis. Lancet 2016;387:1277-1289.

6o. Cassese S, Byrne RA, Ndrepepa G, et al. Everolimus-eluting bioresorbable vascular scaffolds versus everolimus-eluting metallic stents: a meta-analysis of randomised controlled trials. Lancet 2016;387:537-544.

61. Puricel S, Cuculi F, Weissner M, et al. Bioresorbable coronary scaffold thrombosis: multicenter comprehensive analysis of clinical presentation, mechanisms, and predictors. J Am Coll Cardiol 2016;67:921-931.

62. Cuculi F, Puricel S, Jamshidi P, et al. Optical coherence tomography findings in bioresorbable vascular scaffolds thrombosis. Circ Cardiovasc Interv 2015;8:e002518.

63. Raber L, Brugaletta S, Yamaji K, et al. Very late scaffold thrombosis: intracoronary imaging and histopathological and spectroscopic findings. J Am Coll Cardiol 2015;66:1901-1914.

64. Stefanini GG, Byrne RA, Serruys PW, et al. Biodegradable polymer drug-eluting stents reduce the risk of stent thrombosis at 4 years in patients undergoing percutaneous coronary intervention: a pooled analysis of individual patient data from the ISAR-TEST 3, ISAR-TEST 4, and LEADERS randomized trials. Eur Heart J 2012;33:12141222.

65. CAPRIE Steering Committee. A randomised, blinded, trial of clopidogrel versus aspirin in patients at risk of ischaemic events (CAPRIE). Lancet 1996;348:1329-1339. 